\title{
ГИСТОМОРФОМЕТРИЯ ЯИЧЕК И ХАРАКТЕРИСТИКА СПЕРМАТОЗОИДОВ У БАРАНОВ (Ovis aries L.) ПОРОДЫ Lori
}

\author{
S. SOORI, S. MOHAMMADZADEH, M. TAVAFI
}

\begin{abstract}
Порода овец Lori - один из важных генетических ресурсов в регионе Zagros (Иран). Детализированное понимание процессов репродукции у овец этой породы важно для оптимального использования их потенциала. Однако исследования репродуктивных параметров у иранских овец немногочисленны. Настоящая работа была направлена на изучение гистологии яичка и определение показателей качества сперматозоидов у баранов Lori. Для исследования отобрали 10 здоровых особей 2-3-летнего возраста. После забоя семенники удаляли и из эпидидимиса извлекали сперму. Известно, что определение объема семенников и характеристик семенных канальцев служит важным показателем в оценках зрелости и сперматогенеза. Средние значения массы,

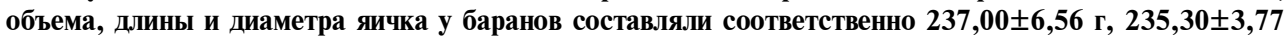
см$^{3}, 9,81 \pm 0,32$ см и 7,63 $\pm 0,42$ см. Исследование гистологических срезов яичка, окрашенных гематоксилином и эозином, показало, что средний диаметр, просвет и высота эпителия в семен-

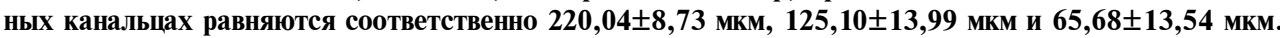
Среднее число клеток Сертоли, сперматогониев, первичных сперматоцитов, вторичных сперматоцитов и сперматид в расчете на каждый срез было соответственно $1,90 \pm 0,87,6,02 \pm 1,44$, $15,30 \pm 5,90,9,65 \pm 3,82$ и 7,60 $\pm 2,63$. Доля подвижных, жизнеспособных и имеющих нормальную морфологию сперматозоидов, извлеченных из придатка яичка, составила соответственно 64,42 $\%, 83,81 \%$ и 90,50 \%. Данные, полученные в настоящем исследовании, могут быть использованы как при размножении породы, так и для углубления знаний в области сравнительной репродуктивной биологии млекопитающих.
\end{abstract}

Ключевые слова: семенники, клетки Сертоли, овцы Lori, морфометрия.

Овцеводство считается основным и наиболее доходным видом деятельности для сельской бедноты в тропических странах. В разных частях мира существует более 1000 различных пород овец при их общем поголовье 1172 млн гол. (1). Овцы Lori (Ovis aries L.) - порода двойного назначения (источник шерсти и мяса), которая подходит для экономически эффективного разведения как в кочевых условиях, так и при сельскохозяйственном производстве (2).

Независимо от вида животных, понимание репродуктивных характеристик служит важным фактором, обеспечивающим рост стада (3). Прикладные исследования сперматогенеза могут быть эффективными для сохранения и улучшения генетической структуры поголовья и, следовательно, повышения репродуктивной способности домашнего скота (4). Существует набор методов оценки репродуктивных качеств у самцов разных видов. Например, применяются измерения с помощью штангенциркуля (5), орхидометрия и ультрасонография у человека и козы $(6,7)$.

Морфометрические обследования выполнены на животных разных видов. Так, сообщалось, что у козы семенные канальцы занимают около

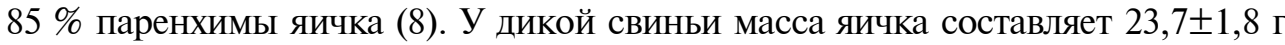
(9). У аравийского барана диаметр семенных канальцев в начале зимы рав-

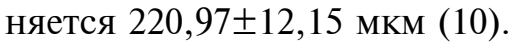

При этом следует отметить, что исследования репродуктивных характеристик иранских овец немногочисленны (11). Результаты, представленные нами в настоящем сообщении, дополняют эти данные.

Целью выполненной работы было определение гистоморфометрических показателей тканей яичка и некоторых характеристик сперматозоидов у баранов породы Lori.

Методика. Оценка качества сперматозоидов. Эксперимент проводили в Колледже сельского хозяйства и природных ресурсов (Agriculture 
and Natural Resources College of Lorestan University) на 10 баранах породы

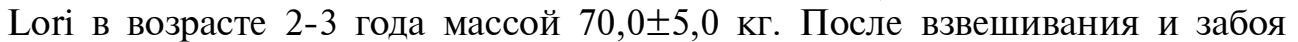
(условия одобрены Комитетом по этике животных - Institutional Animal Ethics Committee, Lorestan University, Khorramabad, 2018) яичко удаляли из мошонки и в нескольких местах надрезали эпидидимис скальпелем для извлечения сперматозоидов; чтобы стимулировать высвобождение спермы из ткани в питательную среду, эпидидимис проминали. Сперму, собранную из придатка яичка, разбавляли цитратом натрия $\left(2,9 \%, 37^{\circ} \mathrm{C}\right)$. Подвижность сперматозоидов оценивали с помощью компьютерного анализа (Computer-aided sperm analysis - CASA, Pro, Way Bulb Type Microscope), регистрировали прямое, зигзагообразное (волнообразное), непоступательное (колебательное) движение и отсутствие движения. Метод окрашивания эозином с нигрозином для дифференциации живых и мертвых сперматозоидов был применен к образцам спермы для определения жизнеспособности и частоты аномалий. Пятно нигрозина увеличивает контраст между фоном и головкой сперматозоида, облегчая визуализацию, а эозин окрашивает только мертвые сперматозоиды (в темно-розовый цвет), тогда как живые спермии остаются неокрашенными. Сперму (5 мкл) смешивали с 20 мкл раствора эозина с нигрозином на предметном стекле (12). Из подготовленных образцов спермы готовили мазки, которые фиксировали воздушной сушкой при комнатной температуре в течение 10 мин перед просмотром. Жизнеспособные сперматозоиды оставались неокрашенными, а мертвые клетки полностью или частично окрашивались в цвет от розового до красного и коричневого. Жизнеспособные спермии далее классифицировали как морфологически нормальные или аномальные в зависимости от морфологии головки, средней части и хвоста. Не менее 200 сперматозоидов были исследованы методом световой микроскопии при увеличении $\times 400$ (13).

Гипоосмотический отек (HOS) характеризует функциональную целостность плазматической мембраны спермиев. Тест HOS (hypo-osmotic swelling test, HOST) оценивает способность мембраны сперматозоидов поддерживать равновесное состояние клетки с окружающей средой. Попадание жидкости из-за гипоосмотического стресса приводит к тому, что хвост сперматозоида скручивается и вздувается («набухает»). Более высокий процент набухших спермиев указывает на наличие клеток, имеющих функциональную и неповрежденную плазматическую мембрану. Сперму (100 мкл) добавляли к 1 мл раствора HOST, осторожно смешивали пипеткой и выдерживали при $37{ }^{\circ} \mathrm{C}$ в течение не менее 30 мин. Просматривали 200 сперматозоидов под микроскопом при увеличении $\times 400$. Все клетки с набухшим хвостом учитывали как живые сперматозоиды $(14,15)$.

Семенники удаляли из мошонки сразу после забоя животного. Диаметр и длину яичек измеряли с помощью цифрового штангенциркуля (точность 10 мкм), массу органа - взвешиванием на цифровых электрических весах. Объем яичка с измерением массы оценивали методом вытеснения воды (принцип Архимеда) $(10,16)$. Использовали формулу [1], где $m$ - масса яичка, г; $V$ - объем яичка, см$^{3}$ :

$$
\rho=\frac{m}{V} \text {. }
$$

Гистологические срезы. Срезы тканей готовили по C.F.A. Culling (17) с модификациями. Методика включала фиксацию (10 \% буферный формалин), дегидратацию (этиловый спирт в возрастающих концентрациях - 50, 70, 90 и $100 \%$ ), очистку (ксилол), насыщение и заливку в парафин. Из парафинированных образцов с помощью микротома готовили срезы толщиной 6 мкм, которые окрашивали гематоксилином и эози- 
ном. Семенной эпителий измеряли при 400-кратном увеличении с использованием калиброванного окулярного микрометра (IS capture-Tucsen). Диаметр семенных канальцев определяли на 5-10 случайно выбранных поперечных срезах с видимо круглыми семенными канальцами (18). Высоту эпителия измеряли в тех же канальцах. Сперматогии имели круглые ядра, для клеток Сертоли характерны нерегулярные ядра (19). Число клеток Сертоли и половых клеток (сперматогонии, первичные и вторичные сперматоциты, сперматиды) определяли при просмотре под микроскопом («Olympus Corporation», Япония) с увеличением $\times 400$ и тестовой сеткой $(15 \times 15 \mathrm{~cm})$. Число канальцев на каждом срезе учитывали под микроскопом при увеличении $\times 100$ по формуле [2]:

$$
V_{v}=\frac{P(y) \times 100}{P(\text { ref })}
$$

где $P(y)$ - сумма точек на срезе; $P(r e f)$ - общее число точек в тестовой сетке (20).

Число первичных сперматогониев, вторичных сперматогониев, клеток Сертоли и сперматид подсчитывали на 10 срезах семенных канальцев круглой или почти круглой формы, выбранных случайным образом.

Для полученных показателей рассчитывали средние значения $(M)$ и стандартные отклонения $( \pm \mathrm{SD})$.

Результаты. Данные, характеризующие качество спермы и морфометрические показатели яичка, представлены в таблицах 1 и 2. Исследование гистологических срезов показало, что семенные канальцы состоят из многослойного зародышевого эпителия, содержашего сперматогонии и клетки Сертоли (рис. 1). Сперматогенез начинается с образования первичного сперматоцита на базальной мембране и продолжается до формирования сперматозоида в центре канальца. Сперматогонии на срезах имели вид крупных сферических клеток, расположенных вокруг семенных канальцев. Более того, в интерстициальной ткани яичек в норме наблюдали клетки Лейдига и миоиды с кровеносными сосудами (рис. 2). Число клеток Сертоли на срезе вблизи сперматогониев было невелико (см. рис. 2).

1. Морфометрические показатели яичек и характеристика спермиев у баранов (Ovis aries L.) породы Lori $(n=10$, Agriculture and Natural Resources College of Lorestan University, Иран)

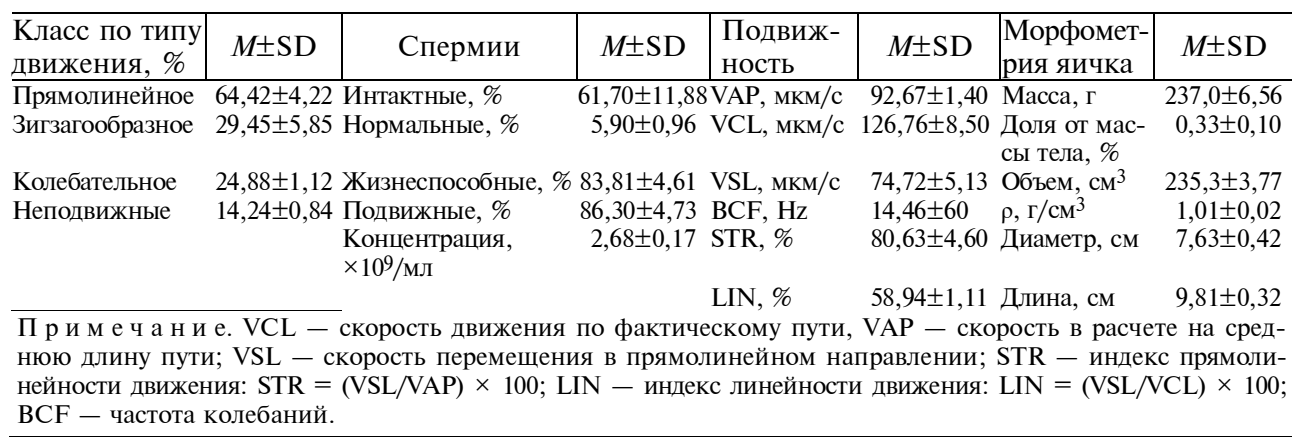

2. Функщиональная характеристика срезов яичка у баранов (Ovis aries L.) породы Lori $(n=10$, Agriculture and Natural Resources College of Lorestan University, Иран)

\begin{tabular}{|c|c|c|c|}
\hline Показатель & $M \pm \mathrm{SD}$ & Показатель & $M \pm \mathrm{SD}$ \\
\hline Диаметр семенных канальцев, мкм & $220,04 \pm 8,73$ & Плотность семенных канальцев, \% & $87,66 \pm 1,99$ \\
\hline Длина эпителия, мкм & $65,68 \pm 13,54$ & Число сосудов на 1 мм² & $1,37 \pm 0,65$ \\
\hline Диаметр просвета, мкм & $125,11 \pm 13,99$ & Длина сменных канальцев на 1 мм³ & $10,09 \pm 2,18$ \\
\hline Число канальцев & $4,95 \pm 1,07$ & Клетки Сертоли, кл/мм² & $1,90 \pm 0,87$ \\
\hline Первичные сперматоциты, кл/мм² & $15,30 \pm 5,90$ & Сперматогонии, кл/мм² & $6,02 \pm 1,44$ \\
\hline Вторичные сперматоциты, кл/мм² & $9,65 \pm 3,82$ & Сперматиды, кл/мм² & $7,60 \pm 2,63$ \\
\hline
\end{tabular}




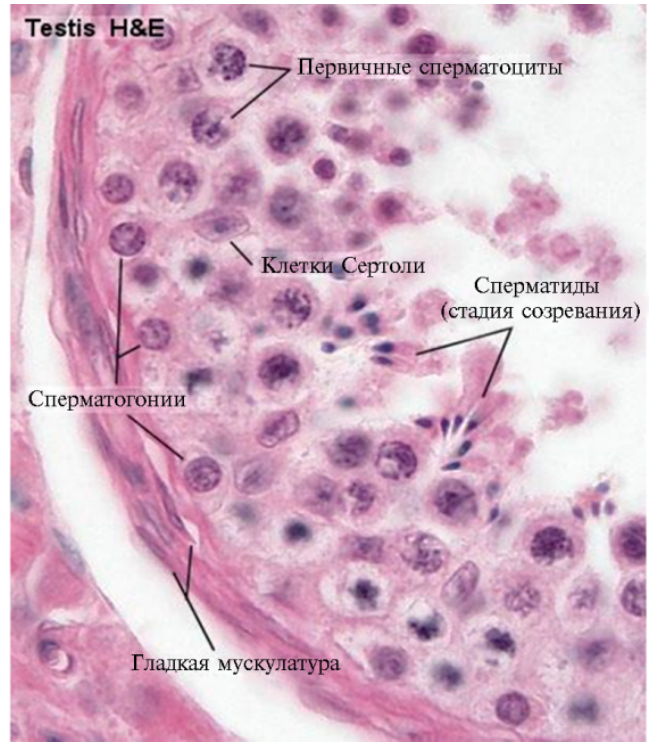

Рис. 1. Разные клетки в семенных канальцах яичка барана (Ovis aries L.) породы Lori. Видны первичные сперматоциты, клетки Сертоли, сперматогонии, сперматиды (стадия созревания) и гладкая мускулатура. Гистологические срезы, окрашивание гематоксилином и эозином, световая микроскопия («Olympus Corporation», Япония), увеличение $\times 400$.

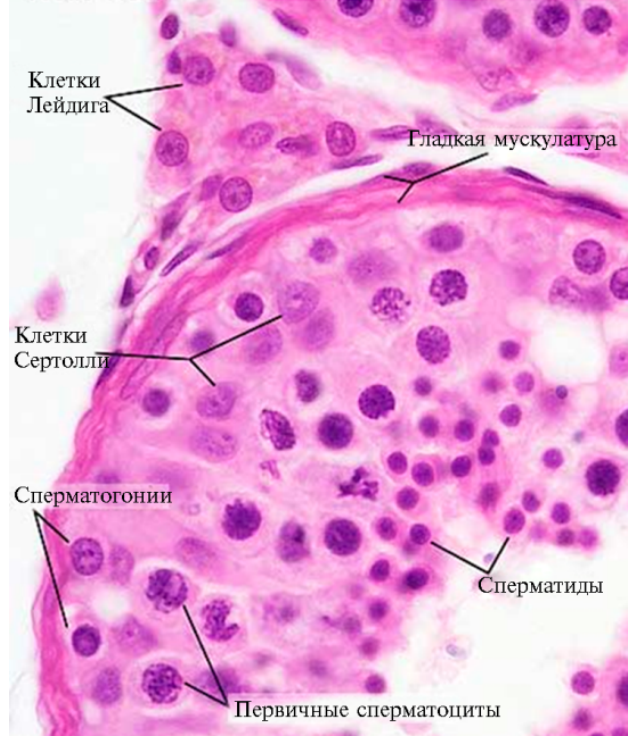

Рис. 2. Интерстициальная ткань, половые клетки и клетки Сертоли в яичке барана (Ovis aries L.) породы Lori. Видны клетки Лейдига и Сертолли, сперматогонии, первичные сперматоциты, сперматиды и гладкая мускулатура. Гистологические срезы, окрашивание гематоксилином и эозином, световая микроскопия («Olympus Corporation», Япония), увеличение $\times 400$.

Диаметр семенных канальцев и высота эпителия семенных каналь-

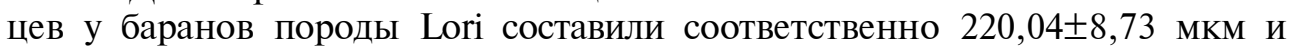
$65,68 \pm 13,54$ мкм, что сходно с данными, полученными у некоторых домашних баранов. Средние диаметры семенных канальцев и высота эпителия семенных канальцев у коз составляли 197,20 и 39,2 мкм соответственно (5). M. Akosman с соавт. (21) установили, что средние диаметры семенных канальцев у голштино-фризской и симментальской пород крупного рогатого скота равнялись соответственно 226,68 и 223,44 мкм. По сообщению S. Arrighic соавт. (13), средний диаметр семенных канальцев у буйволов составляет 243,19 мкм. В целом диаметр семенных канальцев у большинства млекопитающих варьируется от 180 до 350 мкм $(18,22)$.

Объем семенников и характеристики семенных канальцев - важные показатели при оценке зрелости особи и сперматогенеза $(23,24)$. В этом эксперименте параметры яичка у баранов Lori были аналогичны описанным в работах J. Martins с соавт. (25) и S. Mohammadzadeh с coaвт. (5). Подобные данные были получены для баранов Санта-Инес (26) и европейских пород овец - мериносов, Саффолк (Suffolk), Корридейл (Corriedale) и баранов Lori (27). Клетки Сертоли - основные регуляторы развития яичка и эффективности сперматогенеза (28). Образование сперматозоидов в яичках регулируется с участием процессов, связанных с пролиферацией клеток Сертоли, которая происходит до начала половой зрелости. Поскольку клетки Сертоли обеспечивают созревающим спермиям механическую опору, защиту и питание, число клеток Сертоли тесно связано с процессом сперматогенеза (29). В настоящем исследовании клетки Сертоли с треугольными ядрами и расширенной цитоплазмой наблюдались при 400-кратном увеличении.

У разных видов млекопитающих размер яичка у зрелых самцов коррелирует с репродуктивной способностью и общим числом клеток Сер- 


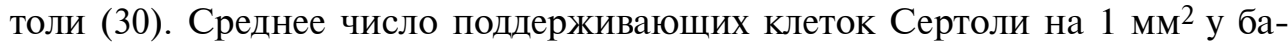

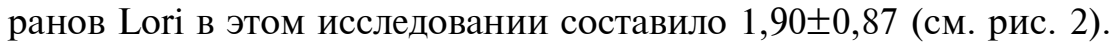

Семенные канальцы - основные компартменты яичка, доля которых у большинства млекопитающих изменялся от 70 до $90 \%$ паренхимы яичка (30). В этом исследовании плотность семенных канальцев у 2-3-

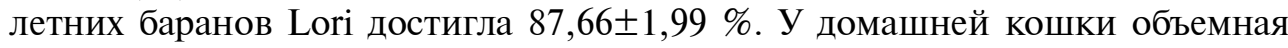
плотность семенных канальцев составляла $90 \%$ (18). В результате этого эксперимента было показано, что большую часть яичка занимают семенные канальцы. Процент семенных канальцев у коз Lori составлял 80-85 \% (5). L.R. Franca и C.L. Godinho (18) сообщили, что процентное содержание семенных канальцев у млекопитающих существенно не различалось (у кроликов, свиней, баранов, жеребцов, кошек и быков соответственно 87, $83,80-87,73,88$ и $81 \%)$. В настоящем исследовании среднее число клеток Сертоли, сперматогониев, первичных и вторичных сперматоцитов на 1 мм $^{2}$ оценивалось соответственно как $1,90 \pm 0,87,6,02 \pm 1,44,15,30 \pm 5,90$,

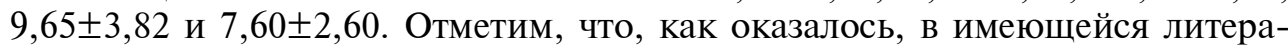
туре соответствующая информация очень скудна.

Таким образом, полученные нами данные показывают, что определение числа клеток, диаметра канальца, объема яичка и других его параметров может помочь в лучшем понимании процесса сперматогенеза у изучаемой аборигенной породы. Поскольку существует высокая корреляция между плотностью семени и сперматогенезом, для оценки последнего важно определять несколько параметров, включая число клеток Лейдига и размер ядра сперматогониев.

\section{ЛИТЕРАТУРА}

1. FAOSTAT. 2016. Statistics Division [Internet]. Food and Agriculture Organization of the United Nations. Available http://faostat.fao.org. Accessed 15.11.2017.

2. Soori M., Nurian Sarvar E. Sheep husbandary. Iran Razi University, Kermanshah, 2007..

3. Silva M.R., Pedrosa V.B., Silva J.C., Eler J.P., Guimaraes J.D., Albuquerque L.G. Testicular traits as selection criteria for young Nellore bulls. J. Anim. Sci., 2011, 89: 2061-2067 (doi: 10.2527/jas.2010-3525).

4. Comizzoli P., Mermillod P., Mauget R. Reproductive biotechnologies for endangered mammalian species. Reprod. Nutr. Dev., 2000, 40(5): 493-504.

5. Mohammadzadeh S., Abasi M., Tavafi M., Kiani A. Reproductive efficiency of an indigenous Iranian goat (Capra hircus). Animal Research International, 2013, 10(2): 1723-1729.

6. Al Salim A., Murchison P.J., Rana A., Elton R.A., Hargreave T.B. Evaluation of testicular volume by three orchidometers compared with ultrasonographic measurements. Br. J. Urol., 1995, 76(5): 632-635.

7. Paltiel H.J., Diamond D.A., Di Canzio J., Zurakowski D., Borer J.G., Atala A.. Testicular volume: comparison of orchidometer and US measurements in dogs. Radiology, 2002, 222(1): 114-119 (doi: 10.1148/radiol.2221001385).

8. Yadav S.K., Sharma A.K. Seminiferous length in normal buffalos-bulls and bucks. International Journal of Animal Science, 1994, 9: 293-296.

9. Costa G.M., Leal M.C., Silva J.V., Ferreira A.C., Guimaraes D.A., Franca L.R. Spermatogenic cycle length and sperm production in a feral pig species (collared peccary, Tayassu tajacu). Journal of Andrology, 2010, 31(2): 221-230 (doi: 10.2164/jandrol.109.008524).

10. Dorostghoal M., Sorooshnia F., Zardkaf A. Stereological analysis of Wistar rat testis during early post-natal development. Anatomia, Histologia, Embryologia, 2011, 40(2): 89-94 (doi: 10.1111/j.1439-0264.2010.01043.x).

11. Ghorbani K., Yarahmadi B. Study of lactation and reproduction characteristics in Lori ram. Research conference of sheep and goat. Iran, 2004 (in Persian).

12. Love C.C. Relationship between sperm motility, morphology and the fertility of stallions. Theriogenology 2011, 6(3): 547-557 (doi: 10.1016/j.theriogenology.2011.03.007).

13. Arrighi S., Bosi G., Groppetti D., Cremonesi F. Morpho- and histometric evaluations on the testis and epididymis in buffalo bulls during the different reproductive seasons. The Open Anatomy Journal, 2010, 2: 29-33 (doi: 10.2174/1877609401002010029).

14. WHO. WHO laboratory manual for the examination and processing of human semen. 5th edition. 
WHO, 2010.

15. Jeyendran R.S., Van der Ven H.H., Perez-Pelaez M., Crabo B.G., Zaneveld L.J. Development of an assay to assess the functional integrity of the human sperm membrane and its relationship to the other sperm characteristics. Journal of Reproduction and Fertility, 1984, 7091): 219-228.

16. Akosman M.S., Özdemir V. Capability of the Cavalieri method for volume estimation of the dog testis. Eurasian Journal of Veterinary Sciences, 2010, 26: 63-67.

17. Culling C.F.A. Handbook of histopathological and histochemical technique. ButterworthHeinemann, Elsevier Ltd., 1974 (doi: 10.1016/C2013-0-04011-X).

18. Franca L.R., Godinho C.L. Testis morphology, seminiferous epithelium cycle length and daily sperm production in domestic cat (Felis catus). Biol. Reprod., 2002, 68(5): 1554-1561 (doi: 10.1095/biolreprod.102.010652).

19. Kishore P.V.S., Geetha R., Sabiha H.B. Postnatal differentiation of spernatogenic cells in the testis of ram. Tamilnadu Journal Veterinary \& Animal Sciences, 2012, 8(6): 340-344 .

20. Tae H.J., Jang B.G., Ahn D.C., Choi E.Y., Kang H.S., Kim N.S., Lee J.H., Park S.Y., Yang H.H., Kim I.S. Morphometric studies on the testis of Korean ring-necked pheasant (Phasianus colchicus karpowi) during the breeding and non-breeding seasons. Vet. Res. Commun., 2005, 29(7): 629-643 (doi: 10.1007/s11259-005-3080-8).

21. Akosman M., Faruk L., Seyin Demirel H. Morphological, stereological and histometrical assessment of the testicular parameters between Holstein and Simmental bulls. International Journal of Morphology, 2013, 31(3): 1076-1081 (doi: 10.4067/S0717-95022013000300048).

22. Ewing L.L., Zirkin B.R., Cochran R.C., Kromann N., Peters C., Ruiz-Bravo N. Testosterone secretion by rat, rabbit, guinea pig, dog, and hamster testes perfused in vitro: correlation with Leydig cell mass. Endocrinology, 1979, 105(5): 1135-1142 (doi: 10.1210/endo-105-5-1135).

23. Osinubi A.A., Noronha C.C., Okanlawon A.O. Morphometric and stereological assessment of the effects of long-term administration of quinine on the morphology of rat testis. West African Journal of Medicine, 2005, 24(3): 200-205.

24. Petersen P.M., Giwercman A., Gundersen H.J.G., Pakkenberg B. Efficient and unbiased tools for quantitating Leydig and Sertoli cells in the testis from testes biopsies. Image Analysis \& Stereology, 2010, 19(2): 113-117 (doi: 10.5566/ias.v19.p113-117).

25. Martins J., Souza C., Campos A., Aguiar G., Lirna A., Araújo A., Neiva J., Moura A. Measurements of reproouctive traits and spermatogenesis in crossbreeo hairy rams. Archivos de Zootecnia, 2008, 57(220): 553-556.

26. Sousa F., Lobo C., Menezes E., Rego J., Oliveira R., Lima-Souza A., Fioramonte M., Gozzo F., Pompeu R., Cândido M., Oliveira J., Moura A. Parameters of the reproductive tract, spermatogenesis, daily sperm production and major seminal plasma proteins of tropically adapted morada nova rams. Reprod. Dom. Anim., 2014, 49(3): 409-419 (doi: 10.1111/rda.12288).

27. Bielli A., Pedrana G., Gastel M.T., Castrillejo A., Morana A., Lundeheim N., Forsberg M., Rodriguez-Martinez H. Influence of grazing management on the seasonal change in testicular morphology in Corriedale rams. Anim. Reprod. Sci., 1999, 56(2): 93-105 (doi: 10.1016/S03784320(99)00027-5).

28. Hess R.A., Cooke P.S., Bunick D., Kirby J.D. Adult testicular enlargement induced by neonatal hypothyroidism is accompanied by increased Sertoli cell and germ cell number. Endocrinology, 1993, 132(6): 2607-2613 (doi: 10.1210/endo.132.6.8504761).

29. Zamiri M.J. Physiology of reproduction. Haghshenas Publication, 2009 (in Persian).

30. Russell L.D. Form, dimensions, and cytology of mammalian Sertoli cells. In: The Sertoli cell /L.D. Russell, M.D. Griswold (eds.). Cache River Press, Clearwater, 1993: 1-37.

Department of animal science, Lorestan University, Lorestan Province, Khorramabad, A81, Iran, e-mail: sori1371@gmail.com, Mohammadzadeh.s@lu.ac.ir $\bowtie$, mtavafi@yahoo.com

\section{TESTICULAR HISTOMORPHOMETRY AND SPERM CHARACTERISTICS IN Lori RAMS (Ovis aries L.)}

\section{S. Soori, S. Mohammadzadeh, M. Tavafi}

Department of animal science, Lorestan University, Lorestan Province, Khorramabad, A81, Iran, e-mail sori1371@gmail.com, Mohammadzadeh.s@lu.ac.ir ( $₫$ corresponding author), mtavafi@yahoo.com ORCID:

Soori S. orcid.org/0000-0002-4216-4914

Mohammadzadeh S. orcid.org/0000-0002-7791-9272

The authors declare no conflict of interests

Received December 21, 2018

Tavafi M. orcid.org/0000-0002-7354-2631 
Lori sheep breed is one of the important genetic resources in the Zagros region of Iran. Accurate knowledge of reproduction of Lori sheep is an essential step for optimal utilization of its potential. The present research aimed to study the testis histology and identify the sperm parameters in Lori rams. Ten healthy rams 2-3 years, were selected. After slaughtering, the testes were removed and epididymis minced to release sperm. The averages of weight, volume, length and diameter of testis were $237.00 \pm 6.56 \mathrm{~g}, 235.30 \pm 3.77 \mathrm{~cm}^{3}, 9.81 \pm 0.32 \mathrm{~cm}$ and $7.63 \pm 0.42 \mathrm{~cm}$, respectively. Study of testicular sections was shown that the mean diameter, lumen and height of epithelium of seminiferous tubules were $220.04 \pm 8.73 \mu \mathrm{m}, 125.10 \pm 13.99 \mu \mathrm{m}$ and $65.68 \pm 13.54 \mu \mathrm{m}$, respectively. The mean number of Sertoli cells, spermatogonia, primary spermatocytes, secondary spermatocytes and spermatids per each section were $1.90 \pm 0.87,6.02 \pm 1.44,15.30 \pm 5.90,9.65 \pm 3.82$ and $7.60 \pm 2.63$, respectively. Rate of motility, viability and normal morphology of released spermatozoa from epididymis were $64.42 \%, 83.81 \%$ and $90.5 \%$, respectively. The knowledge generated in the present study can be used in reproduction for comparative reproductive biology of mammalian species.

Keywords: testis, Sertoli cells, Lori sheep, morphometry.

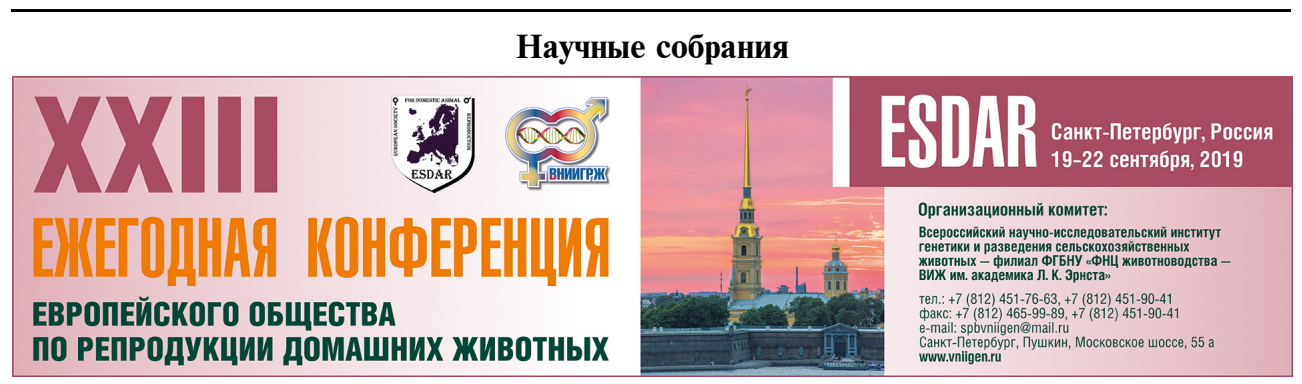

\section{3-я ЕЖЕГОДНАЯ КОНФЕРЕНЦИЯ ЕВРОПЕЙСКОГО ОБЩЕСТВА РЕПРОДУКЦИИ ДОМАШНИХ ЖИВОТНЫХ}

(19-22 сентября 2019 года, г. Санкт-Петербург)

Организаторы конференции: ESDAR (Европейское общество репродукции домашних животных), Санкт-Петербургская государственная академия ветеринарной медицины и Российский научно-исследовательский институт генетики и разведения сельскохозяйственных животных (ВНИИГРЖ).

Конференция проводится во многих европейских странах с 1997 года, впервые она состоится в России в 2019 году.

Деятельность ежегодной конференции ESDAR направлена на то, чтобы собрать вместе специалистов для обсуждения актуальных вопросов репродукции различных видов животных. Репродуктивная биология и биотехнология являются неотъемлемыми блоками конференции в дополнение к традиционной ветеринарной медицине, физиологии и патологии размножения животных.

\section{Ключевые доклады:}

- Взаимодействие эмбриона и матери на ранних сроках беременности: Что мы можем узнать из диабетической модели кролика

- Как большой помет влияет на иммунную систему свиней

- Митохондриальная регуляция подвижности и фертильности спермы

- Качество содержания КРС и воспроизводство

- Воздушно-жидкостная модель клеточной культуры: от эпителия дыхательных путей до половых путей самки

\section{Параллельные семинары}

- Воспроизводство северных оленей

- Потенциальное влияние микробиома на размножение

- Воспроизводство свиней

- Предродовая подготовка и менеджмент крупного рогатого скота (KРC) - интерактивный семинар

- Извлечение яйцеклетки (Ovum pick-up) для практиков (лошади и КРС)

- Размножение диких животных и птиц

- Хромота и воспроизводство КРС

Информация: http://vniigen.ru/

$$
\text { http://www.esdarconferencespb2019.com/ }
$$

